\title{
Research of Community Service Information System
}

\author{
Bei $\mathrm{Li}^{1, \mathrm{a}^{*}}$, Gongfa $\mathrm{Li}^{1, \mathrm{~b}}$ and Heng Tang ${ }^{1, \mathrm{c}}$ \\ ${ }^{1}$ Wuhan University of Science and Technology, China \\ a1198413210@qq.com, bligongfa@wust.edu.cn, ‘464792431@qq.com,
}

Keywords: Community service; Internet service; System construction; Service system; Information system.

\begin{abstract}
Community service information system which is an information network and information management service system of government, subdistrict office, neighborhood committee is established by means of community public e-government network platform. Guaranteeing to establish community service information public network platform and putting up an information system network of community service management information system, community website group, community service call center, forming a service system of accessing information channel, member information certification, united service process and standard. Driving to the development of community service industry comprehensively, increasing community employment, improving educational service level, achieving a high quality goal of information service.
\end{abstract}

\section{Introduction}

At recent years, with the development of information, e-government and e-commerce have a speed development. It is a trend to improve community management system and community public service level for achieving city information. Exploiting new community service system constantly to meet residents' requirements for community information[1-3]. Making full use of market resources, achieving optimization of resources, improving development power of community constantly, guiding in life level of residents and addressing community problems as the goal, establishing community information as purpose [4]. When improving and developing community information, strengthening construction of community public service, improving effectiveness of community management system and implementation process. According to residents' demand trends, collecting to relative service resources and basic information which includes community employment, medical insurance, housewifery education, community health services, cultural level and soon on. Therefore, a comprehensive system - community service information system which is made up of community service call center, community service management system, community website group should be established.

\section{Outline of Community Service Construction}

With the development of information, community information construction can be divided into four aspects according to existing conclusions of community service information construction, shown in Fig. 1.

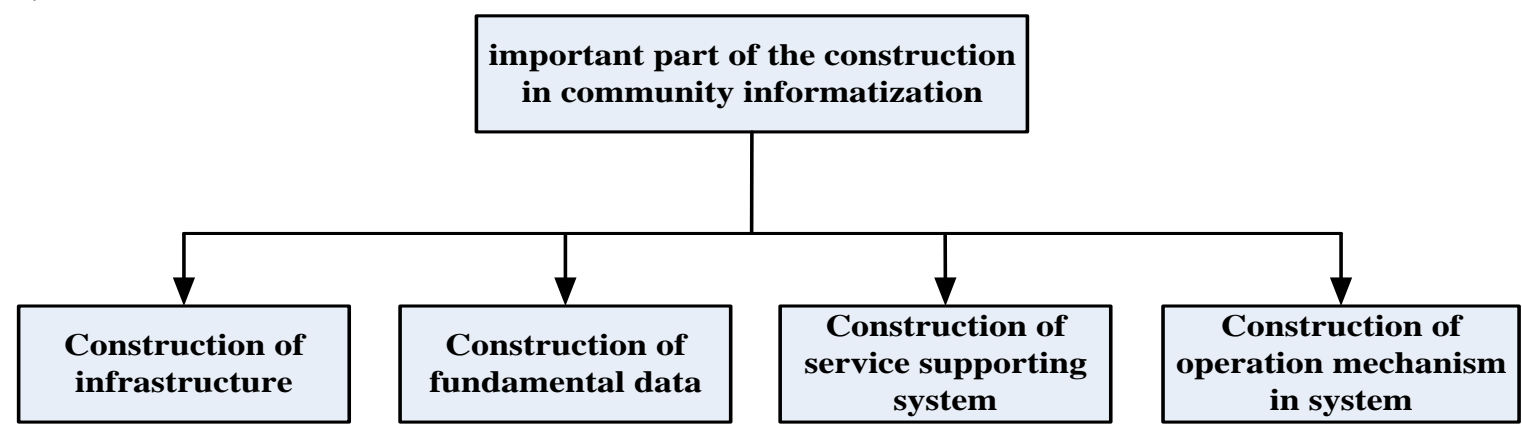

Figure 1. Part of community service construction 
Construction of Infrastructure. Infrastructure is made up of hardware and software. Hardware facilities including internet device, optical fiber, telephone hotline, family computer and software facilities including community service team, community management organization, human resources, property management is established.

Construction of Fundamental Data. Fundamental data including standard specification system, data collection, data exchanging and sharing, moving APP, data evaluation system, comprehensive analysis is established. 1) Establish standard specification system of data, business and length of field. 2) Establish a data information platform based on existing population. 3) Establish a data exchanging and sharing platform. 4) Collect to residents' basic information by APP. 5) Establish a comprehensive data evaluation and analysis system.

Construction of Service Supporting System. Making full use of the advantage of community and introducing donators as service supporting system of constructing community service information system. It will provide a favorable security and greater possibility for community information.

Construction of Operation Mechanism in System. Establishing a service organization above community service information platform, it will provide all kinds of real and reliable information by information network platform. Operation mechanism in community service information system should use to governmental monitoring, upper and lower linkage, supplement each other ensuring real and accurate information.

\section{Construction of Community Service Information System}

City in Beijing, Shanghai and other one line urban have developed maturely in community information. Most of community information system mainly focused on order program, government affairs openness and providing internet for resents. The residents' requirement for community service is shown in Fig. 2.

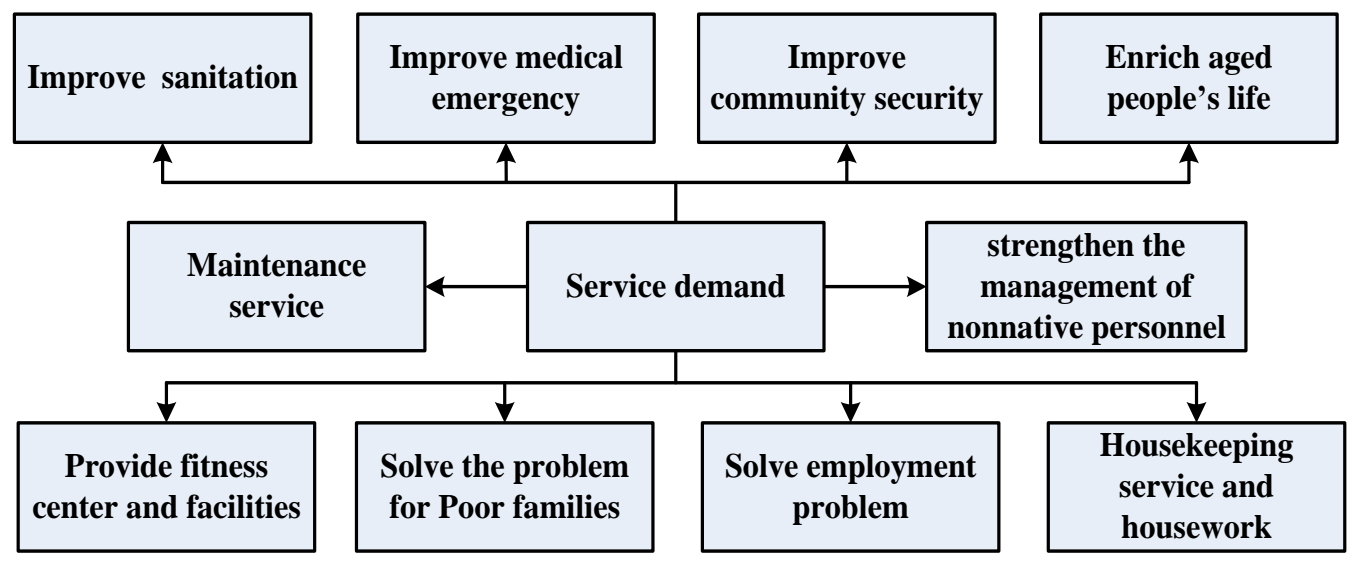

Figure 2. System of residents' demand for community service

Structure of Community Service Information. Community service information system will become a ordered whole not a single function by establishing to structure network of information system and three network of government, subdistrict office and neighborhood committee [5]. It is very important to put into larger proportion in educational culture, community medical insurance, employment, community security and growth. Its work flow chart is shown in Fig. 3. Relying on this network structure and lining three departments to interact each other, it can well deal with the problem between community public service and enjoying the achievement of community construction. 


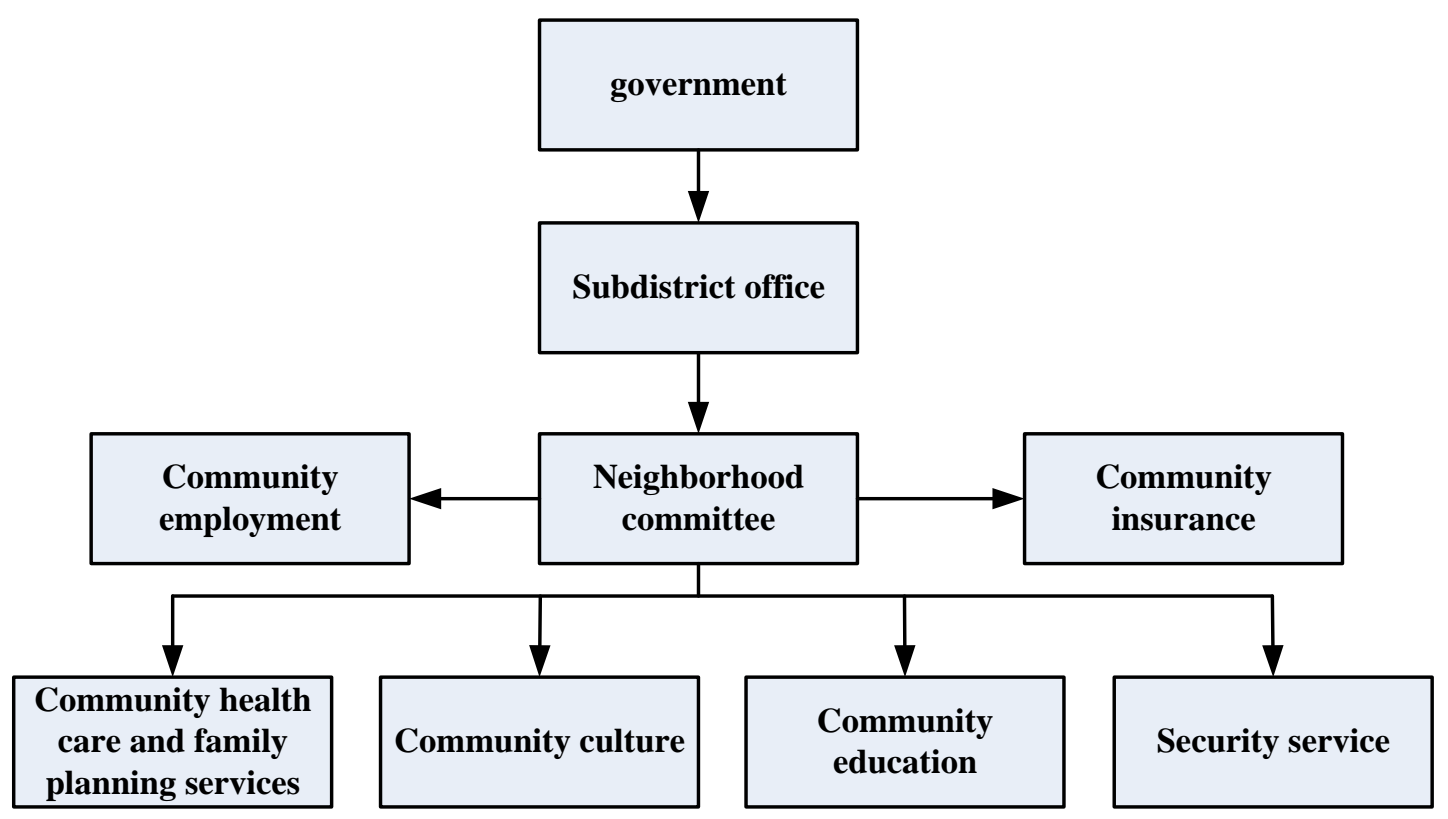

Figure 3. Community service information network

Framework of Community Service Information System. Establishing a comprehensive covering community information network pattern of community website group, community service call center and information management system by a series of construction system [6].

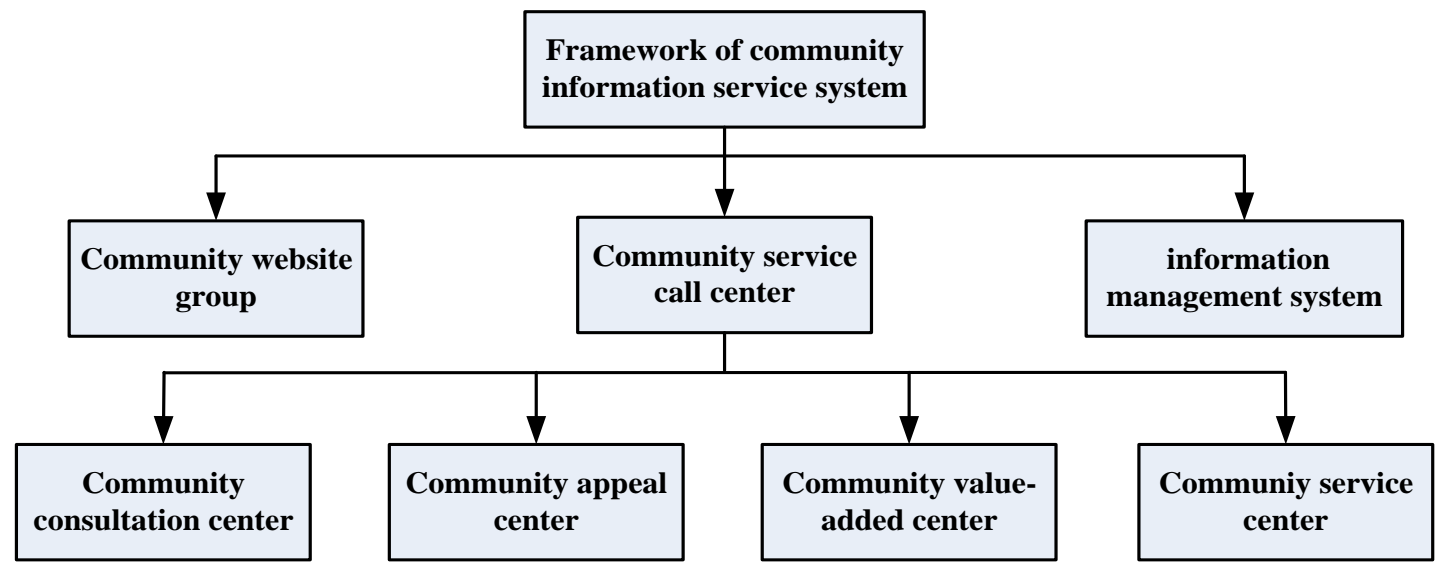

Figure 4. Community service information system

Community website group which is relying on public e-government information platform serves community residents by internet. Work efficiency of every department can be improved by this website group, making its advantage more and more significant.

Community service call center is made up of four parts which is consultation center, appeal center, value-added center, and service center [7]. 1) Establishing a consultation center of providing latest information data for community residents. 2) Establishing an appeal center of service attitude evaluation. 3) Establishing a value-added center of providing value-added service. 4) Establishing a service center of developing public welfare community service and guiding community service.

Community service information management system includes neighborhood committee management system and center management system [8]. 1) Establishing a neighborhood committee management system to deal with all kinds of business information. 2) Establishing a center management information system to analyze and integrate information data. 


\section{Development Potential of Community Service Information System}

Means which the government develop community information have achieved the construction of community service information system. It involves with employment, medical insurance, housekeeping, e-government and e-commerce, community security [9-10]. The breakthrough point is found to develop community information. It will drive community residents' consciousness of community information, providing a greater development space and considerable market for e-commerce. Community service information system is not a single system but an important system commanding internet, information service call center and community service information management system. It drives the educational and commercial industry development, promoting the economic construction and the development of city.

\section{Conclusion}

The trend in developing community information is more and more obvious. Through the overview in this paper, giving full play to the potential advantages of community service, creating a service information community by the joint efforts of various functional departments. Configuration of community service resources is optimized and infrastructure is improved. It has improved administrative code of community service and established a feasibility system in the construction of community service information management system. Operation process of this system is more reasonable, having achieved unified standard. A relatively complete system of information community service is formed in the construction of community service information system. It is the real wisdom convenient community for people which provides a possibility of not leaving home for community residents.

\section{References}

[1] Z.Z. Lin, T. Zhou and Z.H. Zhou, et al: Application of Information System for Community Health Service in Guangdong Province. China Medical Herald, Vol. 12(2015) No.9, p.47-51

[2] Q. Yan, G.W. Huang and J.C. Zhang, et al: A Study on the Issue of Community Health Service Information System Construction. Chinese Primary Health Care, Vol. 26(2012) No.3, p.20-22

[3] W. Li, J. Zhong and F. Li: The Analysis of the Demands and Strategies of Community Health Service Information Systems in Shandong Province. Journal of Community Medicine, Vol.9 (2011) No.1, p.2-4

[4] Q. Yan, G.W. Huang and J.C. Zhang: Major Issue and Countermeasure for Community Health Service Information System Construction. Chinese General Practice, Vol.14 (2011) No.12A, p.3909-3910

[5] Y.J. Jia, Y. Yu: Design of Web-based Information System for Health Services in Community. Modern Electronics Technique, Vol.37 (2014) No.8, p.87-90

[6] Y. Ren, D. Sun: Preliminary Discussion on the Construction of Community Health Services Information System. Journal of Henan Mechanical and Electrical Engineering College, Vol.20 (2012) No.3, p.34-36

[7] C.W. Zhang: The Development of Community Grids Service Integrated Platform. Library and Information Service, Vol.55 (2011) No.11, p.56-61

[8] L.M. Wang, Y.Y. Han and T. Lei: Design of a Car Repair Management System. Microcomputer and its Applications, Vol.32 (2013) No.16, p.11-16

[9] X. Li, L.P. Guo and Z.G. Wang: Some Suggestions for the Construction of Community Public Service in Handan. Journal of Handan Polytechnic College, Vol.26 (2013) No.3, p.32-34 
[10] W. Wei, J. Chen and K.P. Wang: Architecture of Community Public Services Platform Based on SOA and Its Application. Computer Technology and Development, Vol.24 (2014) No.10, p.48-54. 